\title{
Low Speed Estimation of Sensorless DTC Induction Motor Drive Using MRAS with Neuro Fuzzy Adaptive Controller
}

\author{
Mini R. ${ }^{1}$, Shabana Backer P. ${ }^{2}$, B. Hariram Satheesh ${ }^{3}$, Dinesh M. N. ${ }^{4}$ \\ ${ }^{1}$ Department of Electrical and Electronics Engineering, Amrita School of Engineering, Bengaluru, \\ Amrita VishwaVidyapeetham, Amrita University, and VTU Research scholar, India \\ ${ }^{2}$ Department of Electrical and Electronics, Amrita School of Engineering, Bengaluru, \\ Amrita VishwaVidyapeetham, India \\ ${ }^{3}$ ABB GISL, Bangalore, India \\ ${ }^{4} \mathrm{R}$ V College of Engineering, Bangalore, India
}

\begin{abstract}
Article Info
Article history:

Received Sep 7, 2017

Revised Jan 31, 2018

Accepted Jul 21, 2018

\section{Keyword:}

Adaptive controller

DTC

IMD

Induction motor

MRAS

NFC

ABSTRACT

This paper presents a closed loop Model Reference Adaptive system (MRAS) observer with artificial intelligent Nuero fuzzy controller (NFC) as the adaptation technique to mitigate the low speed estimation issues and to improvise the performance of the Sensorless Direct Torque Controlled (DTC) Induction Motor Drives (IMD). Rotor flux MRAS and reactive power MRAS with NFC is explored and detailed analysis is carried out for low speed estimation. Comparative analysis between rotor flux MRAS and reactive power MRAS with PI as well as NFC as adaptive controller is performed and results are presented in this paper. The comparative analysis among these four speed estimation methods shows that reactive power MRAS with NFC as adaptation mechanism shows reduced speed estimation error and actual speed error at steady state operating conditions when the drive is subjected to low speed operation. Simulation carried out using MATLAB-Simulink software to validate the performance of the drive
\end{abstract}

PI controller

\section{Corresponding Author:}

Mini R,

Faculty Electrical and Electronics Department, Amrita School of Engineering,

Bengaluru, Amrita VishwaVidyapeetham, Amrita University,

and VTU Research scholar, +919449232429, India.

Email: minir_sujithr@yahoo.com,mini_sujith@blr.amrita.edu
Copyright (C) 2018 Institute of Advanced Engineering and Science. All rights reserved.

\section{INTRODUCTION}

Sensorless DTC induction motor drives plays a major role in high performance industrial applications due to its instantaneous torque and speed control resulting in fast torque and speed response [1]-[3]. In DTC drive, the optimal inverter switching voltage vectors [4] selects the selection of required torque and flux. The switching state of the inverter is determined by space vector modulation (SVM).The torque and flux ripples are reduced in SVM DTC compared to conventional DTC [5],[21]. Sensorless drives have the advantages of reduced hardware complexity, cost, robustness and reliability of the drive etc. However, the sensorless techniques depend on machine parameter, which varies with temperature, saturation levels, integrator drift and dc offset. Hence conventional speed estimators are not giving accurate speed estimation in the low speed ranges due to which the steady state and transient performance of the drive deteriorates [6].Various methods of speed estimators like open loop and closed loop observers are available in literature. The closed loop estimators have the correction term to improve the performance of estimator than in open loop estimators.

MRAS is a stable, good performance, simple closed loop observer for speed estimation in Induction Motor Drive (IMD). MRAS consists of reference model, an adaptive model and an adaptation mechanism. 
The adaptation mechanism reduces the error between these two models and outputs the estimated value of rotor speed which is equal to the actual rotor speed [4]. MRAS is broadly classified as a) rotor flux MRAS b) back emf MRAS c) reactive power MRAS based on the formulation of speed tuning signal. Of these three methods, rotor flux MRAS is simple and most commonly used MRAS scheme and reactive power MRAS is independent of stator resistance and integrator issues which are the major concern in low speed estimation [4],[20], [7]-[8]. In this paper a detailed investigation is carried out for low speed estimation of DTC IMD using rotor flux MRAS and reactive power MRAS with PI controller as adaptation technique and also PI controller is replaced by Neuro Fuzzy controller as the adaptation technique. A detailed comparison of performance of these four methods are carried out and results shows that the reactive power MRAS with NFC gives good results for low speed estimation issues. Simulation is performed in MATLAB-Simulink platform to validate the results.

\section{SPEED SENSORLESS DTC-SVM}

DTC-SVM controls the flux and electromagnetic torque directly by the selection of exact stator voltage vector. The selection of correct stator voltage vector is based on the output signals from torque and flux PI controller to meet the desired torque and flux requirements of the drive. In DTC-SVM the torque ripples are reduced and switching frequency is maintained constant compared to conventional hysteresis band DTC controllers [9]. Many techniques are available for speed estimation in sensorless drives.

MRAS is used here to estimate speed and the output of the MRAS which is the estimated rotor speed is compared with the reference value of the rotor speed and the error is fed to speed controller to generate the torque reference and flux reference. The generated torque reference and flux reference are compared with the estimated values of torque and flux by the torque and flux estimator. The torque error and flux error obtained are tuned by the corresponding PI controllers to generate the reference voltage vector required for the SVM to select the required stator voltage vector to exactly compensate the flux and torque error. SVM reduces the torque ripple and switching frequency is maintained constant [17],[18].

\section{MODEL REFERENCE ADAPTIVE SYSTEM (MRAS)}

Speed estimation based on MRAS is one of the best techniques due to its simplicity, good performance and stability [6]. In MRAS the reference model estimator is based on stator voltage model which does not contain the rotor speed parameter and adjustable model is based on current model which contains the rotor speed. The basic concept of MRAS is that the reference model and adaptive model independently estimates the required machine parameter using measured stator voltages and currents in the corresponding reference frame, in this work stationary reference frame is considered. The parameter estimated by the reference model and adaptive models are compared and the difference between them is the speed-tuning signal, which is tuned using an adaptation technique, and adjusts the adaptive model to reduce the error between them to zero. When the error between reference and adaptive model reduced to zero, the estimated speed is equal to the actual rotor speed of the drive. The adaptation mechanism should satisfy the Popov's criterion of hyper stability. Based on the speed-tuning signal MRAS can be classified in to three types, Rotor flux MRAS, Back emf MRAS and Reactive power MRAS and the mathematical equations for reference model and adaptive models are givenin [17].

In most of the industrial drives, PI controllers are used as adaptation technique because of its simple structure and satisfactory performance for speed estimation. Due to machine parameter variation and different operating condition, the performance of the drive may not give expected results with PI adaptive controller [10],[11]. Artificial intelligence based controllers are found more effective for speed estimation because it offers reduced tuning efforts and insensitive to parameter variation. In this paper detailed analysis of rotor flux and reactive power MRAS with Neuro Fuzzy controller as adaptation method is carried out and analyzed the performance with PI controller as adaptive mechanism. The results show that reactive power MRAS with Neuro Fuzzy controller (NFC) gives more accurate speed estimation results. Comparative analysis is carried out to validate the effectiveness of NFC as adaptive controller for low speed estimation of DTC induction motor drive.

Neuro fuzzy is a powerful artificial intelligent control method available for control systems. NFC is the combination of a fuzzy-logic controller with the structure of a neural network and it offers the advantages of both fuzzy logic and neural networks [12],[13]. Fuzzy controllers lack the formal learning procedure and ANN lack a clear correlation with the physical problem[14],[15]. NFC combines the learning power of neural network with the capability of fuzzy logic to use expert human knowledge [6]. Tedious manual tuning is required to achieve the structure of fuzzy controller. In NFC, fuzzy system is trained by the neural network learning algorithm having expert human knowledge and learning ability. The hybrid learning algorithm of 
unsupervised and supervised methods is used to reduce the training time [16],[17],[19],[20]. The unsupervised learning generates the number of fuzzy sets, fuzzy rules, rules themselves and the centers and widths of the membership sets. This information is used to make neuro fuzzy controller initially and it gets trained by supervised gradient decent back propagation algorithm to tune the centers and widths of the membership functions.

The two main architectures which can be used for NFC are Mamdani-method and Takagi-Sugeno method. Takagi-Sugeno uses weighted average to compute the crisp output but Mamdani uses the method of defuzzification of a fuzzy output and it has output membership functions and hence the defuzzification process is time consuming and complex. Mamdani method is most commonly used for decision support applications and Takagi-Sugeno is suitable for dynamic non linear control applications. Hence in this work Takagi-Sugeno type neuro fuzzy controller is used.

\subsection{Structure of Neuro Fuzzy Controller (NFC)}

Takagi-Sugeno type neuro fuzzy controller consists of five layers and the structure of NFC is shown in Figure 1. Functions of each layer are given below.

a. Layer 1: Input layer

The first layer is the input layer and it has two inputs. The speed tuning signal which is the error between reference model and adaptive model is one of the inputs and change in error is the second input. No computation is carried out in this layer, it passes the input values to next layer and the link weight in layer 1 is unity. Let error at any instant is denoted as $\varepsilon_{\mathrm{r}}(\mathrm{k})$ and change in error as $\Delta \varepsilon_{\mathrm{r}}(\mathrm{k})=\varepsilon_{\mathrm{r}}(\mathrm{k})-\varepsilon_{\mathrm{r}}(\mathrm{k}-1)$.

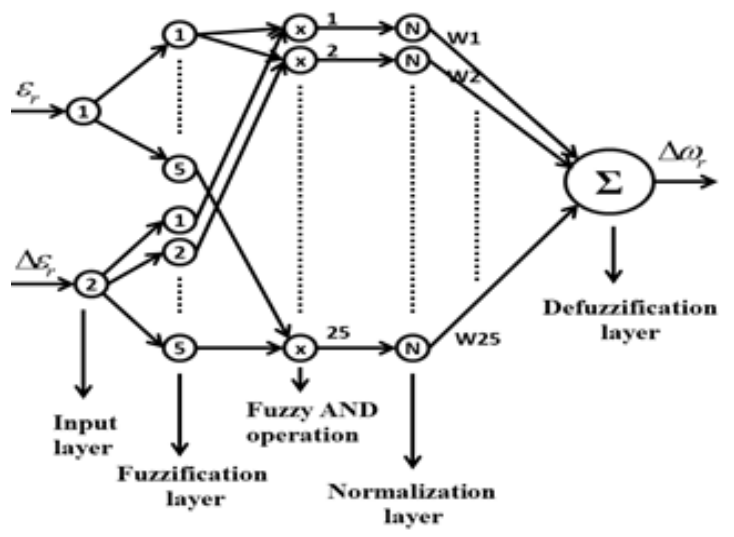

Figure 1. Basic structure of NFC

\section{b. Layer 2: Fuzzification layer}

The second layer is for membership sets where membership functions are defined for each input. Different types of membership functions like triangular wave form, trapezoidal, Gaussian, Sigmoid etc are available for defining membership functions and the selection of exact type of function is based on applications. For applications that need dynamic variation in short period of time triangular waveform is the best choice. Triangular membership functions are used here and as shown in Figure 2.

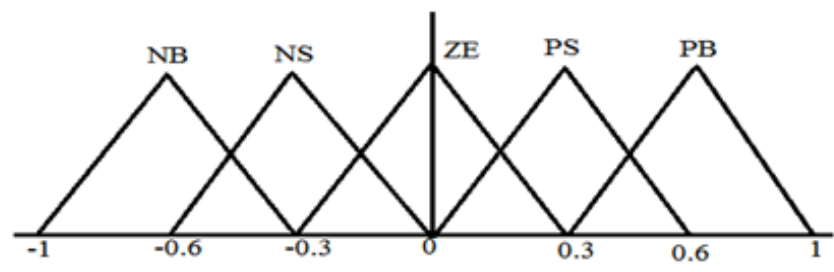

Figure 2. Input membership function for NFC 
Here five membership functions are defined for each input to optimize the computational burden and to achieve best drive performance. When the number of membership function increases, the number of rules will also increases. This will cause high computational burden for NFC. The expression for finding the input membership value for triangular membership function is given here.

$$
\mu_{1 i}=\mu_{2 j}=\left\{\begin{array}{lc}
0 & x<a>c \\
\frac{x-a}{b-a} & a \leq x \leq b \\
\frac{c-x}{c-b} & b \leq x \leq c
\end{array}\right\}
$$

Where $\mathrm{i}=\mathrm{j}=1,2 \ldots . .5$

$x$ represents the input to the fuzzification layer, 'a', 'b' and 'c' represents the left, centre and right limit of a triangular membership function. Layer 2 calculates the output link membership value, showing the degree to which an input value belongs to a fuzzy set. After fuzzification crisp value of inputs are transformed into corresponding fuzzy values. The link weights between the second and third layers are all unity and constant.

c. Layer 3: Fuzzy AND operation

The layer 3 defines the preconditions of the rule nodes, each node in this layer multiply the incoming signal and outputs to the next layer. The expression for node equation is given by equation 2 .

$$
o_{k}^{(3)}=\mu_{1 i} * \mu_{2 j}
$$

Since there are two inputs to NFC and each having five membership function, twenty five nodes are there in this layer to get all the possibilities of rules. The link weights between the third and fourth layer is also unity. The firing strength of the corresponding fuzzy rule is available at the output of each node in this layer.

d. Layer 4: Normalization layer

Each node in this layer calculates the normalized firing strength of each rule, i.e. average firing activity of its corresponding rule. The number of nodes in this layer is same as the number of rules. The node expression for this layer is given as follows

$$
O_{k}^{(4)}=\frac{o_{k}^{(3)}}{\sum o_{k}^{(3)}}
$$

Each output of this layer is multiplied by the interconnection weights between layer 4 and 5 .

e. Layer 5: Defuzzification layer

This layer is the output layer which gives the summation of all incoming signals and the expression for finding the output is:

$$
O^{(5)}=\Delta \omega_{\mathrm{r}}=\sum W_{k} O_{k}^{(4)}
$$

The estimated rotor speed of the drive is obtained by integrating the defuzzified output of the $5^{\text {th }}$ layer.

\subsection{Learning Algorithm for NFC}

The input membership functions are tuned by trial and error method. Supervised gradient descent algorithm is used to update the weights between layer 4 and layer 5 (W1, W2...W25) to minimize the error between reference and adaptive model. In this method squared error is considered proportional to the negative gradient of error with respect to weight and this algorithm is used for the weight updation. Hence it goes gradually towards optimum solution to minimize the error. The error to be minimized is given in equation 5 .

$$
J(k)=\frac{1}{2}(y-\hat{y})^{2}=\frac{1}{2} \varepsilon_{r}^{2}
$$

Where $\varepsilon_{r}$ is the error between reference and adaptive model. The weight adaptation is obtained by equation 6 .

$$
W_{i}(k+1)=W_{i}(k)-\gamma \frac{\partial J(k)}{\partial W_{i}(k)}
$$

where $\gamma$ is the learning rate 


$$
\begin{aligned}
& \frac{\partial J(k)}{\partial W_{i}(k)}=\frac{\partial J(k)}{\partial \hat{y}} \cdot \frac{\partial \hat{y}}{\partial \Delta \omega_{r}} \cdot \frac{\partial \Delta \omega_{r}}{\partial W_{i}} \\
& \frac{\partial J(k)}{\partial \hat{y}}=-(y-\hat{y})=-\varepsilon_{r} \\
& \frac{\partial \Delta \omega_{r}}{\partial W_{i}}=O_{k}^{(4)} \text { is the normalized firing strength of each rule. }
\end{aligned}
$$

$\frac{\partial \hat{y}}{\partial \Delta \omega_{r}}$ is the gradient of reactive power with respect to the output of the controller that is the change of estimated rotor speed. By equation 12, when the estimated rotor speed increases the reactive power calculated by adaptive model also increases. There for this gradient is approximated as positive constant value. According to the nature of gradient descent search for the iterative algorithm convergence, only the sign of this gradient is considering. So the weight updation equation is obtained as

$$
W_{i}(k+1)=W_{i}(k)+\gamma \varepsilon_{r} O_{k}^{(4)}
$$

The estimated speed using this equation is not providing accurate performance due to slow convergence. To solve this issue the change in error i.e. derivative of error is also included with the error. The learning rate $\gamma$ is separated in to two learning terms, $\gamma \& \beta$ for error and change in error respectively. There for the updated weight tuning is given by equation 23 .

$$
W_{i}(k+1)=W_{i}(k)+\left(\gamma \varepsilon_{r}(k)+\beta \Delta \varepsilon_{r}(k)\right) O_{k}^{(4)}
$$

The dynamic performance of the IM drive depends on the values of $\gamma \& \beta$ and these values can be analyzed by a discrete Lyapunov function.

\section{SIMULATION RESULTS AND ANALYSIS}

A 20hp sensorless DTC controlled induction motor drives with speed estimator as MRAS observer with rotor flux and reactive power schemes are simulated in MATLAB-Simulink software. The motor parameters are given in Table I. A detailed simulation analysis is performed to validate the effectiveness of reactive power MRAS with PI as adaptive controller for low speed estimation to enhance the drive performance for a wide range of speed including zero speed. To reduce the burden of PI tuning and to enhance the drive performance at low speed region adaptive PI controller in MRAS is replaced by artificial intelligent Neuro fuzzy controller. An exhaustive analysis is carried out with MRAS observer with rotor flux and reactive power schemes with PI and NFC as adaptive controllers and simulation results are compared and shown in this paper.

Table 1. Machine Parameter

\begin{tabular}{cc}
\hline Parameter & Value \\
\hline $\mathrm{R}_{\mathrm{s}}$ & $0.2147 \Omega$ \\
$\mathrm{R}_{\mathrm{r}}$ & $0.2205 \Omega$ \\
$\mathrm{L}_{\mathrm{s}}$ & $0.065181 \mathrm{H}$ \\
$\mathrm{L}_{\mathrm{r}}$ & $0.065181 \mathrm{H}$ \\
$\mathrm{L}_{\mathrm{m}}$ & $0.06419 \mathrm{H}$ \\
Speed & $1460 \mathrm{rpm}$ \\
Torque & $98 \mathrm{Nm}$ \\
Poles & 4 \\
Voltage & $400 \mathrm{~V}$ (line to line) \\
Frequency & $50 \mathrm{~Hz}$ \\
Inertia & $0.102 \mathrm{Kg} \cdot \mathrm{m}^{2}$ \\
\hline
\end{tabular}

\subsection{Performance of the IMD Using Rotor Flux MRAS with NFC as Adaptive Controller and Comparison with PI as Adaptive Controller}

Simulation is carried out to validate the performance of the drive for a wide range of speed from rated to very low speed including zero speed under rated torque and varying torque conditions. The results are promising and it shows that the estimation of speed and torque are tracking with reference and actual values of the drive. The plots of speed and torque subjected to rated torque of $98 \mathrm{Nm}$ with positive speed and 
positive torque for 0 to $1 \mathrm{~s}$ and negative speed and negative torque from 1 to $2 \mathrm{~s}$ for 1 rpm is shown in Figure 3.

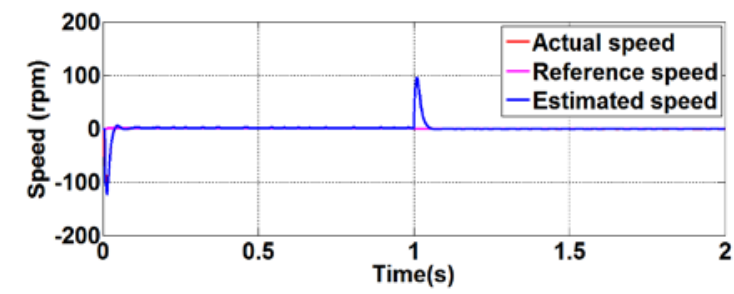

(a)

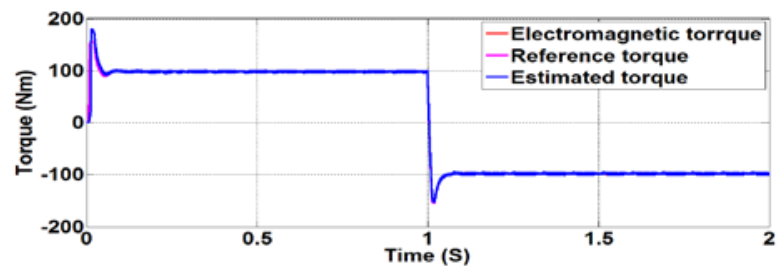

(b)

Figure 3. Speed (rpm) and Torque (Nm) curves using rotor flux MRAS with PI adaptive controller showing reference, estimated and actual values along $\mathrm{Y}$-axis and time in seconds on X-axis for 1rpm.

(a) speed curve (b) torque curve

Simulation results of rotor flux MRAS with NFC as adaptation mechanism shows that the estimated speed is converging with actual speed and reference speed for all ranges of speeds from rated value to very low speed including zero speed. To validate the speed estimation effectiveness at varying torque conditions, the drive is subjected to $3 / 4$ th, $1 / 2$ ndand $1 / 4$ th of rated torque. The speed and torque performance of the drive is analyzed for various speeds under the above torque conditions and Figure 4 shows the estimated, actual and reference speed and torque curves for $3 \mathrm{rpm}$ at the torque condition given in Table 2 .

Table 2. Profile of the Reference Torque Applied

\begin{tabular}{ccccc}
\hline Torque $(\mathrm{Nm})$ & 98 & 73.5 & 49 & 24.5 \\
\hline Time $(\mathrm{s})$ & $0-1$ & $1-2$ & $2-3$ & $3-4$ \\
\hline
\end{tabular}

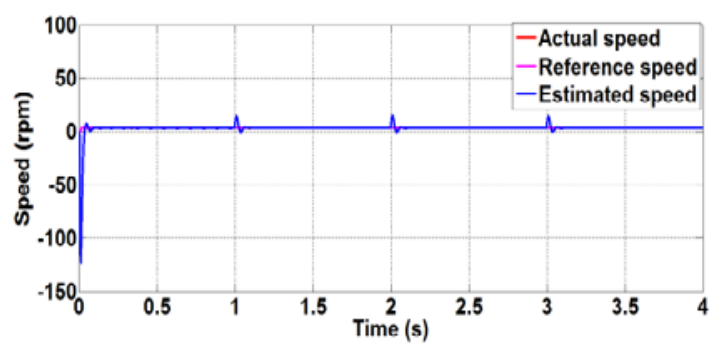

(a)

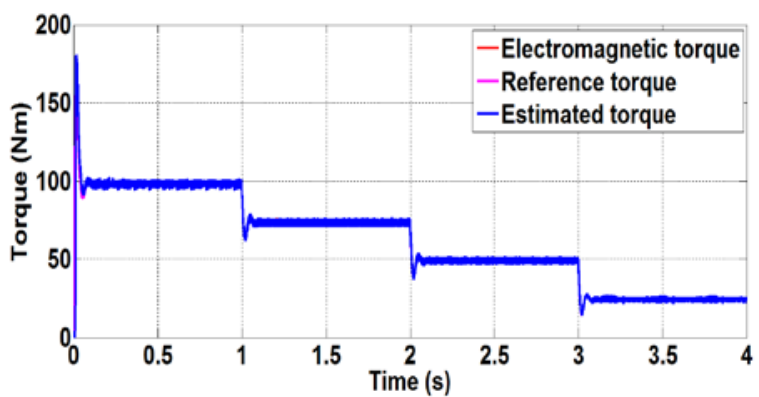

(b)

Figure 4. Speed (rpm) and Torque (Nm) curves showing reference, estimated and actual values along Y-axis and time in seconds on $\mathrm{X}$-axis for $3 \mathrm{rpm}$ at rated, $3 / 4^{\text {th }}, 1 / 2^{\text {nd }}$ and $1 / 4^{\text {th }}$ load condition using rotor flux MRAS with PI as adaptive controller a) speed curve. b) torque curve 
Different steady state performance parameter like percentage error in estimated value, actual value in speed and maximum ripples in speed as well as electromagnetic torque and estimated torque ripples analyzed for rated speed to $1 \mathrm{rpm}$ as given in Table 3.

Table 3. Performance Parameter At Steady State For Rotor Flux MRAS With NFC As Adaptive Controller

\begin{tabular}{ccccccc}
\hline Speed (rpm) & $\begin{array}{c}\text { Speed } \\
\text { Estimation } \\
\text { error (\%) }\end{array}$ & $\begin{array}{c}\text { Actual } \\
\text { speed error } \\
(\%)\end{array}$ & $\begin{array}{c}\text { Ripple in } \\
\text { actual speed } \\
(\mathrm{rpm})\end{array}$ & $\begin{array}{c}\text { Ripple in } \\
\text { estimated } \\
\text { speed (rpm) }\end{array}$ & $\begin{array}{c}\text { Ripple in } \\
\text { electromagnetic } \\
\text { torque (Nm) }\end{array}$ & $\begin{array}{c}\text { Ripple in } \\
\text { estimated } \\
\text { torque (Nm) }\end{array}$ \\
\hline 1 & 19.8 & 51.95 & 0.9003 & 0.8908 & 6.72 & 6.72 \\
2 & 6.274 & 25.93 & 0.781 & 0.779 & 6.85 & 6.85 \\
3 & 3.721 & 15.51 & 0.731 & 0.728 & 6.7 & 6.7 \\
5 & 2 & 9.52 & 0.75 & 0.75 & 6.15 & 6.15 \\
10 & 0.99 & 4 & 0.618 & 0.62 & 6.53 & 6.53 \\
30 & 0.3144 & 1.034 & 0.38 & 0.38 & 6.17 & 6.17 \\
50 & 0.1722 & 0.5073 & 0.27 & 0.25 & 6.8 & 6.8 \\
100 & 0.09099 & 0.2183 & 0.31 & 0.32 & 7.7 & 7.7 \\
300 & 0.02786 & 0.089 & 0.4 & 0.4 & 11.33 & 11.33 \\
500 & 0.01316 & 0.05512 & 0.46 & 0.45 & 13.1 & 13.1 \\
1000 & 0.0056 & 0.034 & 0.63 & 0.63 & 17.11 & 17.11 \\
1460 & 0.0026 & 0.028 & 0.73 & 0.74 & 14.18 & 14.18 \\
\hline
\end{tabular}

The percentage speed estimation error is less than 7\% for speeds from 2rpm to rated speed and it is $19.8 \%$ for $1 \mathrm{rpm}$. The actual speed error is less than $26 \%$ for speeds from $2 \mathrm{rpm}$ to rated speed and it is $52 \%$ for 1rpm. The stator flux trajectory is drawn for 3rpm by plotting the direct and quadrature stator flux components are shown in Figure 5.

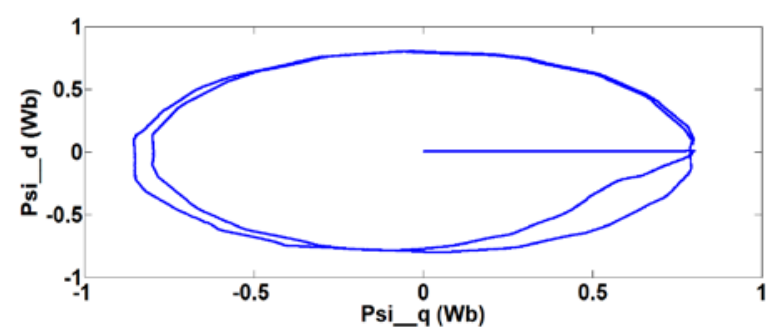

Figure 5. Stator flux trajectory of MRAS (rotor flux) with PI adaptive controller for 3rpm

The drive using rotor flux MRAS with PI as adaptive controller analysis are given in [17]. The comparative analysis of rotor flux MRAS with PI as adaptive controller as well as NFC as adaptive controller are given in Figure 6.

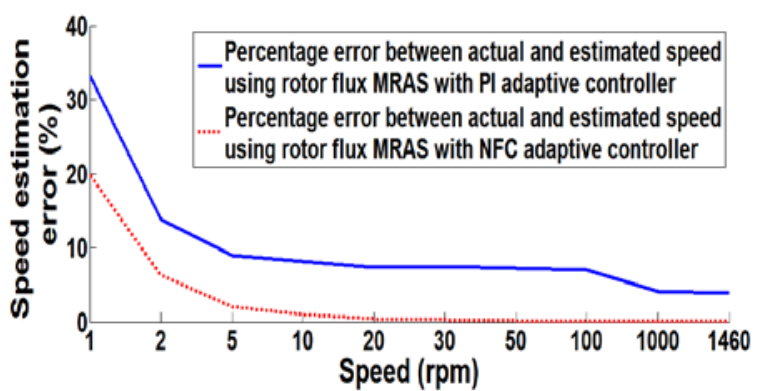

(a)

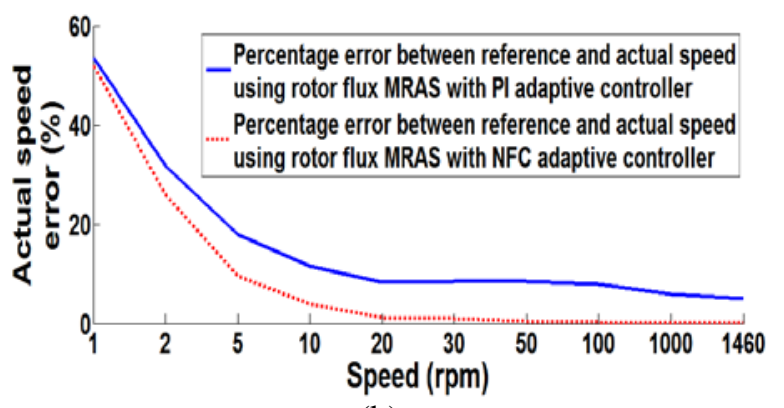

(b)

Figure 6. Speed (rpm) and Torque (Nm) curves using reactive power MRAS with NFC as adaptive controller showing reference, estimated and actual values along $\mathrm{Y}$-axis and time in seconds on $\mathrm{X}$-axis for 1rpm.

a) speed curve. b) torque curve 


\subsection{Performance of the IMD Using Reactive Power MRAS with NFC as Adaptive Controller and Comparison with PI as Adaptive Controller}

Simulation is carried out to analyze the performance of the drive using reactive power MRAS with NFC as adaptive controller for speed ranges from zero to rated speed under rated and varying torque conditions. The results show that estimated and actual values of speed and torque are tracking with reference values of speed and torque. Figure 7. shows the plots of drive subjected to positive speed of $1 \mathrm{rpm}$ and positive rated torque of $98 \mathrm{Nm}$ for 0 to $1 \mathrm{~s}$ and negative speed of $-1 \mathrm{rpm}$ and negative rated torque from 1 to 2 s.
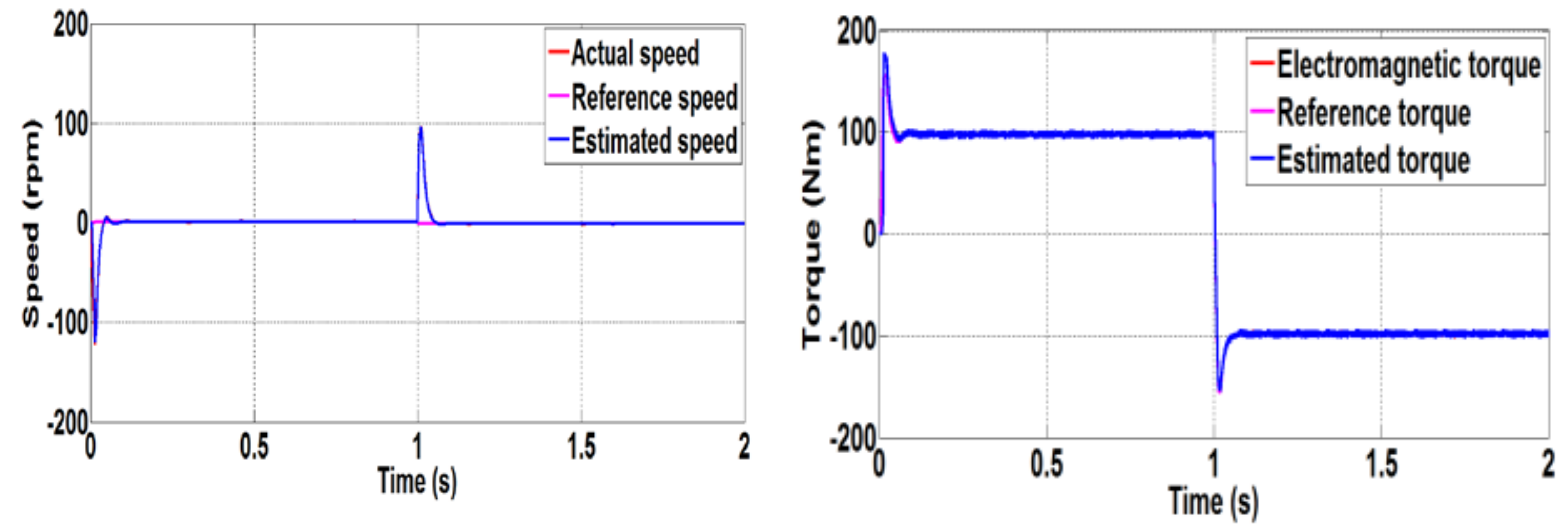

Figure 7. Speed (rpm) and Torque (Nm) curves using reactive power MRAS with NFC as adaptive controller showing reference, estimated and actual values along $\mathrm{Y}$-axis and time in seconds on $\mathrm{X}$-axis for 1rpm.

a) speed curve. b) torque curve

Simulation results of reactive power MRAS with NFC as adaptation mechanism for various speeds gives that the estimated and actual speeds are converging with reference speed from very low speed including zero speed to rated speed. To validate the effectiveness of speed estimation at varying torque condition, the drive is subjected to $3 / 4$ th, $1 / 2$ ndand $1 / 4$ th of rated torque. The performance of the speed and torque are analyzed for various speeds under the above mentioned torque conditions. Figure 8 shows the reference, actual and estimated speed and torque curves for $3 \mathrm{rpm}$ at the torque condition given in Table 2 .

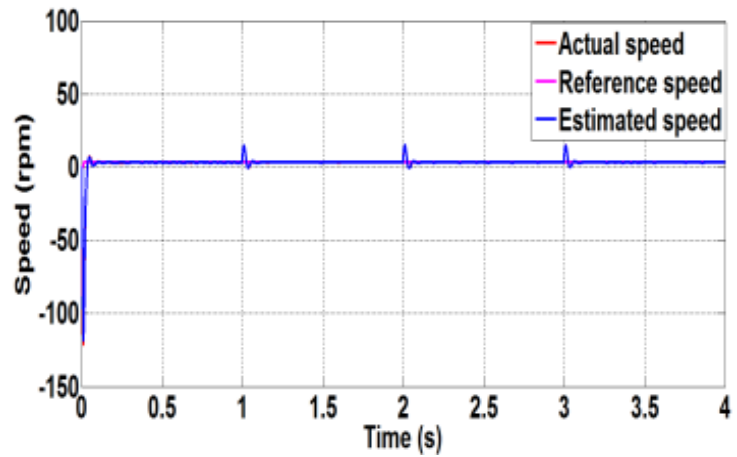

(a)

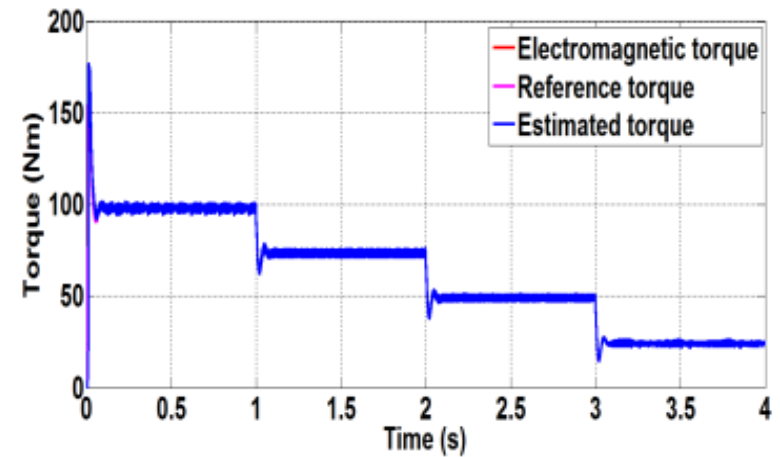

(b)

Figure 8. Speed (rpm) and Torque (Nm) curves showing reference, estimated and actual values along $\mathrm{Y}$-axis and time in seconds on X-axis for 3rpm at rated, 3/4th, 1/2nd and 1/4th load condition using reactive power MRAS with NFC as adaptive a) controller speed curve. b) torque curve

Steady state performance parameter like percentage error in estimated and actual values of speed, ripples in actual and and estimated speed and electromagnetic torque and estimated torque ripples are analyzed for rated speed to 1rpm are given in Table. 4. 
Table 4. Performance Parameter At Steady State For Reactive Power MRAS with NFC Adaptive Controller

\begin{tabular}{ccccccc}
\hline Speed (rpm) & $\begin{array}{c}\text { Speed } \\
\text { Estimation } \\
\text { error (\%) }\end{array}$ & $\begin{array}{c}\text { Actual } \\
\text { speed } \\
\text { error (\%) }\end{array}$ & $\begin{array}{c}\text { Ripple in } \\
\text { actual speed } \\
\text { (rpm) }\end{array}$ & $\begin{array}{c}\text { Ripple in } \\
\text { estimated } \\
\text { speed (rpm) }\end{array}$ & $\begin{array}{c}\text { Ripple in } \\
\text { electromagnetic } \\
\text { torque (Nm) }\end{array}$ & $\begin{array}{c}\text { Ripple in } \\
\text { estimated } \\
\text { torque (Nm) }\end{array}$ \\
\hline 1 & 10.5 & 42 & 0.8427 & 0.827 & 6.64 & 6.64 \\
2 & 3 & 20 & 0.721 & 0.748 & 6.71 & 6.71 \\
3 & 1.366 & 15 & 0.844 & 0.848 & 6.85 & 6.85 \\
5 & 0.4875 & 8 & 0.755 & 0.76 & 6.4 & 6.4 \\
10 & 0.21 & 3.1 & 0.64 & 0.6 & 6.3 & 6.3 \\
30 & 0.068 & 0.648 & 0.33 & 0.33 & 6.2 & 6.2 \\
50 & 0.06 & 0.3 & 0.29 & 0.29 & 6.74 & 6.74 \\
100 & 0.048 & 0.15 & 0.302 & 0.32 & 7.4 & 7.4 \\
300 & 0.01 & 0.058 & 0.34 & 0.36 & 9.36 & 9.36 \\
500 & 0.0116 & 0.0375 & 0.37 & 0.41 & 13.16 & 13.16 \\
1000 & 0.0064 & 0.027 & 0.5 & 0.58 & 17.05 & 17.05 \\
1460 & 0.00325 & 0.02 & 0.64 & 0.7 & 13.8 & 13.8 \\
\hline
\end{tabular}

The percentage speed estimation error is less than 3\% for speeds from $2 \mathrm{rpm}$ to rated speed and it is $10.5 \%$ for $1 \mathrm{rpm}$. The actual speed error is less than $20 \%$ for speeds from $2 \mathrm{rpm}$ to rated speed and it is $42 \%$ for 1rpm. The stator flux trajectory is drawn for 3rpm by plotting the direct and quadrature stator flux components are shown in Figure 9.

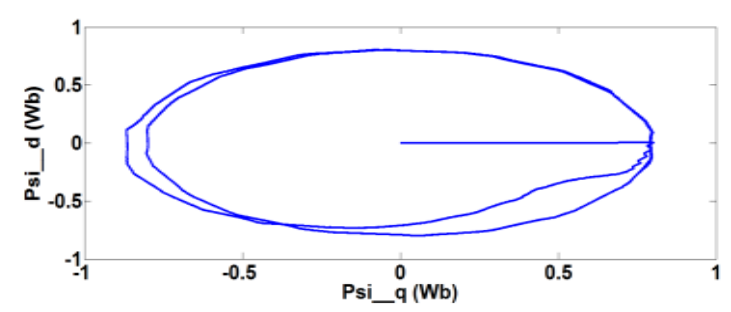

Figure 9. Stator flux trajectory of reactive power MRAS with PI adaptive controller for 3rpm

The drive using reactive power MRAS with PI as adaptive controller analysis are given in [17]. The comparative analysis of reactive power MRAS with PI as adaptive controller as well as NFC as adaptive controller are given below in Figure 10.

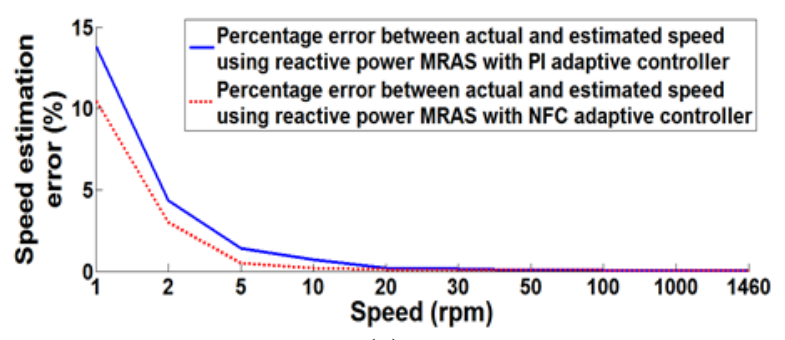

(a)

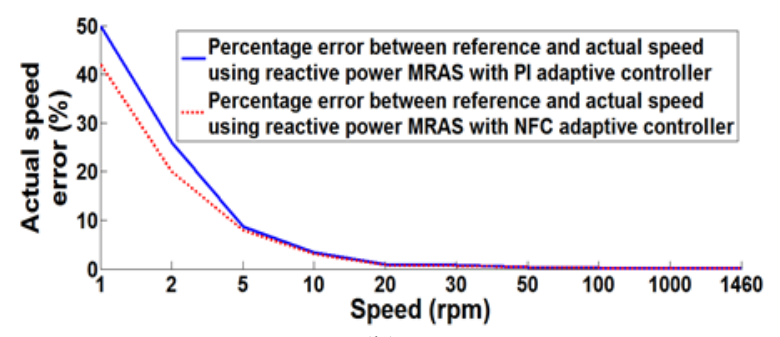

(b)

Figure 10. (a) Speed estimation error profile for different speeds using reactive power MRAS with PI adaptive controller and NFC adaptive controller and (b) Actual speed error profile for different speeds using reactive power MRAS with PI adaptive controller and NFC adaptive controller

\subsection{Performance Analysis Comparison of IMD Using Rotor Flux MRAS and Reactive Power MRAS with PI as Adaptive Controller and NFC as Adaptive Controller}

A detailed comparative analysis of all the four techniques used for low speed estimation in sensorless DTC IMD is carried out and the comparative analysis of percentage of speed estimation error and actual speed error in shown in Figure 11(a) and (b) respectively. Figure 12 (a) and (b) shows the comparison 
of ripples in actual speed and estimated speed using all the four approaches considered for low speed estimation using MRAS and Figure 13 shows ripple
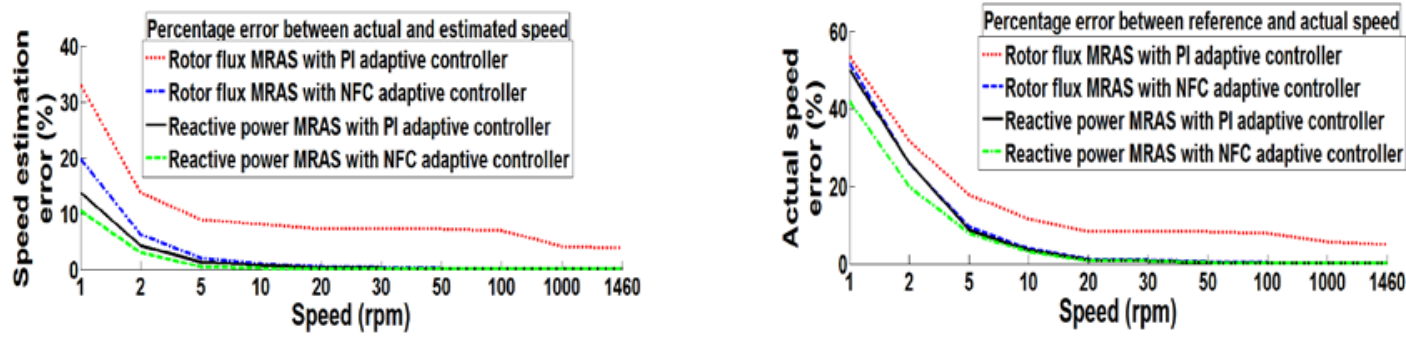

Figure 11. (a) Speed estimation error profile for different speeds in MRAS with rotor flux and reactive power with PI adaptive controller and NFC adaptive controller and (b) Actual speed error profile for different speeds in MRAS with rotor flux and reactive power with PI adaptive controller and NFC adaptive controller
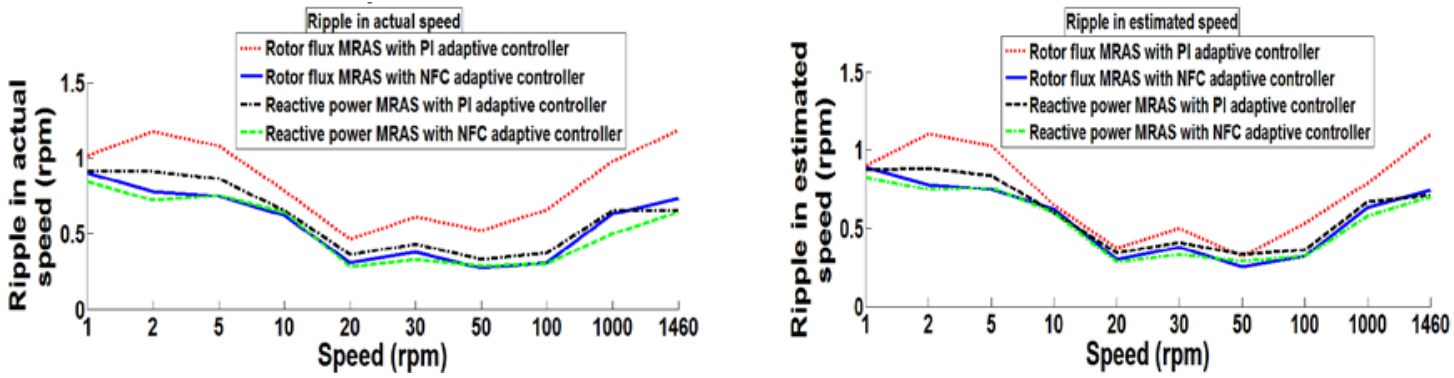

Figure 12. Ripple in actual speed profile for different speeds in MRAS with rotor flux and reactive power with PI adaptive controller and NFC adaptive controller and (b) Ripple in estimated speed profile for different speeds in MRAS with rotor flux and reactive power with PI adaptive controller and NFC adaptive controller.
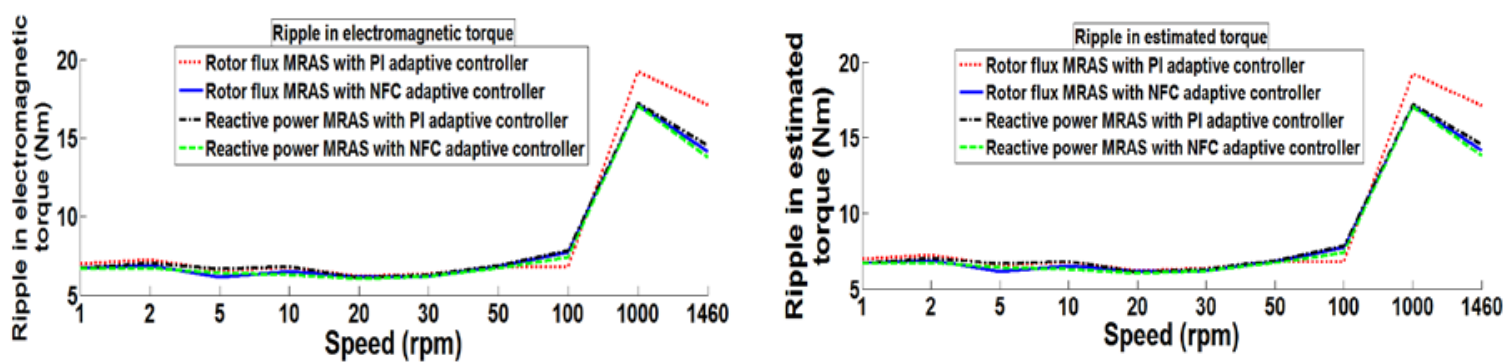

Figure 13. Ripple in actual electromagnetic torque profile for different speeds in MRAS with rotor flux and reactive power with PI adaptive controller and NFC adaptive controller and (b) Ripple in estimated torque profile for different speeds speeds in MRAS with rotor flux and reactive power with PI adaptive controller and NFC adaptive controller

\section{CONCLUSION}

In this paper reactive power MRAS is used as speed estimator to improve the performance of speed estimation especially at low ranges of speed which is a research challenge in sensorless direct torque controlled induction motor drives. Simulation of a 20hp DTC IMD with rotor flux MRAS and reactive power MRAS for speed estimation with PI controller as its adaptation technique is done to validate the drive performance at low speeds. To reduce the tedious PI tuning effort and to improve the performance of speed 
estimation at low speeds including zero speed artificial intelligent based Neuro fuzzy controllers is used as the adaptation technique.

Extensive analysis is performed by simulation at varying torque conditions with speed and torque reversals to validate the performance of the drive in steady state and transient conditions in the low speed ranges with PI as well as NFC as adaptive controllers. Various performance parameters like percentage error in estimated and actual values in speed and torque, ripples in estimated and actual values in speed and torque from rated speed to low ranges is carried out. The results show the effectiveness of reactive power MRAS estimator in low speed region and the performance improvement of the drive with NFC as adaptive controller. Comparison of all the above performance parameters of the drive with PI as well as NFC as adaptive controller for MRAS proves the effectiveness of MRAS with NFC adaptive controller as speed estimator for the low speed estimation issues in sensorless DTC IM drives.

\section{REFERENCES}

[1] I. Takahashi and T. Noguchi, "A new quick-response and high-efficiency control strategy of an induction motor," IEEE Trans. Ind. Applicat., vol. 22, pp. 820-827, Sept./Oct. 1986.

[2] T. G. Habetler and F. Profumo, "Direct torque control of induction machines using space vector modulation," IEEE Trans. Ind. Applicat., vol. 28, pp. 1045-1052, Sept./Oct. 1992.

[3] C. Lascu, I. Boldea and F. Blaabjerg, "A modified direct torque control (DTC) for induction motor sensorless drive,” Industry application confererence, vol. 1, pp. 415-422, Oct. 1998.

[4] P. Vas,- Sensorless vector and direct torque control \| Oxford Newyork Tokyo, Oxford university press,1998.

[5] Y. S. Lai and J. H. Chen, "A new approach to direct torque control of induction motor drives for constant inverter switching frequency and torque ripple reduction,” IEEE Trans. Energy Conversion, vol. 16, pp. 220-227, Sept. 2001.

[6] J. Holtz and J. Quan, “ Sensorless vector control of induction motors at very low speed using a nonlinear inverter model and parameter identification,” IEEE Trans. Ind. Applicat., vol. 38, pp. 1087-1095, July/Aug. 2002.

[7] S. Maiti, C. Chakraborty, Y. Hori and Minh c. Ta, "Mpdel reference adaptive controller-based rotor resistance and speed estimation technique for vector controlled induction motor drive utilizing reacive power," IEEE Trans. Ind. Electronics, vol.55, pp. 594-601, Feb. 2008.

[8] Mrs. M. Nandhini Gayathri, Dr. S. Himavathi and Dr. R. Sankaran, "Comparison of rotor flux and reactive power based MRAS rotor resistance estimators for vector controlled induction motor drive,” IEEE-International Conference On Advances In Engineering, Science And Management, pp. 183-189, March. 2012.

[9] Z. Zhang, R. Tang, B.Bai and D, Xie, "Novel direct torque control bades on space vector mpdulation with adaptive stator flux observer for induction motors,”IEEE Trans. On magnetics, vol. 46, pp. 3133-3136, Aug. 2010.

[10] S. M. Gadoue, D. Giaouris and J. W. Finch, "MRAS sensorless vector control of induction motor using new sliding-mode and fuzzy logic adaptation mechanisms,” IEEE Trans. On Energy Conversion, vol. 25, pp. 394-402, June. 2010.

[11] M. Rashed and A. F. Stronach, "A stable back-EMF MRAS-based sensorless low speed induction motor drive insensitive to stator resistance variation,” Inst. Electr. Eng. Proc. Electr. Power Appl., vol. 151, no. 6, pp. 685-693, Nov. 2004.

[12] M. Nasir Uddin, Z. Rui Huang, A. B. M. Siddique Hossain, "Development and implementation of a simplified selftuned neuro-fuzzy based IM drive,” IEEE Trans. Ind. Applicat., vol. 50, pp. 51-59, Jan./Feb. 2014.

[13] M. Zerikat, S. Chekroun, A. Meherence, "Fuzzy-neural networks controller-based adaptation mechanism for MRAS sensorless induction motor drives. ELECTROMOTION 2009 - EPE Chapter 'Electric Drives' Joint Symposium, July 2009.

[14] M. N. Uddin and M. I. Chy, "A novel fuzzy logic controller based torque and flux controls of IPM synchronous motor,” IEEE Trans. Ind. Appl., vol. 46, no. 3, pp. 1220-1229, May/Jun. 2010.

[15] F. J. Lin, C. H. Lin, P. H. Shen, "Self-Constructing Fuzzy Neural Network Speed Controller for Permanent-Magnet Synchronous Motor Drive”, IEEE Trans. on Fuzzy Systems, vol.9, No.5, pp.751-759, 2001.

[16] Teresa Orlowska-Kowalska, Mateusz Dybkwski and Krzysztot Szabat, "Adaptive neuro fuzzy control of the sensorless induction motor drive system,” EPE-PEMC 2006.

[17] Mini. R, Shabana Backer. P, Dr. Hariram Satheesh, Dr. Dinesh M. N, "MRAS speed observer for low speed estimation in sensorless DTC-SVM induction motor drives”, IJAER, ISSN 0973-4562 Vol.10, No.5, pp.39793985,2015.

[18] Mini.R, RaniSreenivasan, Dr.DineshM.N, " Low Speed Estimation of DTC controlled Induction motor drive using MRAS " IEEE International Conference on Electronics, Communication and Computational Engineering(ICECCE), pp. 30-35, 2014.

[19] Mohammed, H. and Meroufel, A., 2015. Contribution to the Artifical Neural Network Speed Estimator in a Degraded Mode for Sensor-Less Fuzzy Direct Control of Torque Application Using Dual Stars Induction Machine. International Journal of Electrical and Computer Engineering, 5(4), p.729.

[20] Pirouzmand, F., 2014. Robust Model Predictive Control Based on MRAS for Satellite Attitude Control System. International Journal of Electrical and Computer Engineering, 4(1), p.81.

[21] Rajendran R, Devarajan N. Simulation and implementation of a high performance torque control scheme of IM utilizing FPGA. International Journal of Electrical and Computer Engineering. 2012 Jun 1;2(3):277. 


\section{BIOGRAPHIES OF AUTHORS}

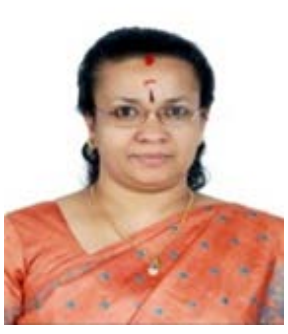

Mini.R obtained her B.Tech. Degree in Electrical Engineering from Kerala university and M.Tech in Power Electronics from Visvewaraye Technological University (VTU). She is currently pursuing her Ph.D. in VTU on Electric Drives and Controlsl. With 9 years of industial experience, she has been with the Amrita School of Engineering, Bangalore Campus, Amrita Vishwa Vidyapeetham (University), India since 2002. She is currently Assistant Professor (Selection Grade) of the Department of Electrical Engineering.

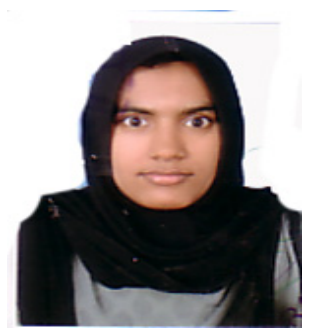

Shabana P Backer obtained her M.Tech in Power Electronics from Amrita Vishwa Vidyapeetham, Amrita University, Bangalore Campus.

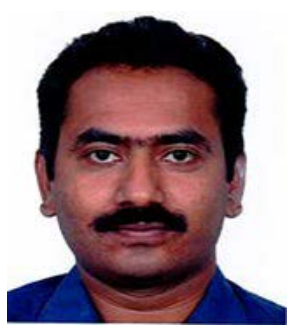

Dr. B. Hariram Satheesh obtained his B.E. in Electrical and Electronics Engineering from Manonmanium Sundaravar University, M.Tech in Industrial Drives from Mysore University and Ph.D. from Anna University. He has 12 years of experience in accademics and 10 years of Industrial experience. He is currently working as Principal Scientist in ABB and has several publications.

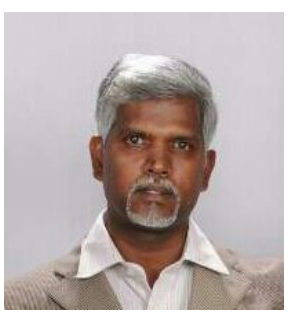

Dr. Dinesh M.N obtained his B.E in Electrical Engineering and M.E in Power Systems from Bangalore University and Ph.D.from Visvewaraye Technological University (VTU). He has 27 years of teaching experience. He has several publications and his research interests are Power Electronics, Control Systems, High voltage insulators, Electric Drives. 